\title{
"Pseudo" cholelithiasis: sequelae of minimally invasive cholecystectomy with maximum surprise - an unusual case
}

Laparoscopic cholecystectomy is the gold standard for managing cholecystolithiasis, despite being associated with a higher incidence of gallbladder perforations (10\%-40\%) [1] and spillage of gallstones $(6 \%-30 \%)$ than is the open procedure. Although rare $(0.08 \%-0.3 \%)$ [2], gallstone spillage could potentially lead to serious morbidity such as gallstone abscesses, which can present from as early as 1 month to as late as 20 years after the procedure, almost anywhere in the abdominal cavity [3].

A female patient underwent an apparently uneventful laparoscopic cholecystectomy 3 years back. She was referred to us with clinical and radiological signs suggestive of "residual" cholecystitis. Her magnetic resonance cholangiography showed an apparently anatomically intact gallbladder containing multiple stones and a low-inserting cystic duct with features suggestive of calculous cholecystitis ( $\bullet$ Fig. 1 and Fig. 2). The coronal section ( $\bullet$ Fig. 3 ) confirmed these findings.

However, to our surprise, diagnostic laparoscopy revealed a walled-off abscess cavity at the gallbladder fossa containing $30-40 \mathrm{ml}$ frank pus with multiple gallstones giving a deceptively identical appearance to a "nonextracted" gallbladder. There was no trace of residual actual gallbladder or cystic duct. The patient recovered well after laparoscopic drainage of the abscess with removal of stones.

This unique postcholecystectomy appearance of MR images could have confused the second surgeon while putting the previous surgeon at a risk of serious litigation. It could well be called a "pseudo" cholelithiasis. Such a deceptive appearance has not been reported before.

In today's era of laparoscopic cholecystectomy, if this possibility were to be considered, it would reduce the number of false-positive diagnoses of "residual" cholelithiasis wherein a diagnostic laparoscopy and drainage (as in this case) could significantly reduce the access

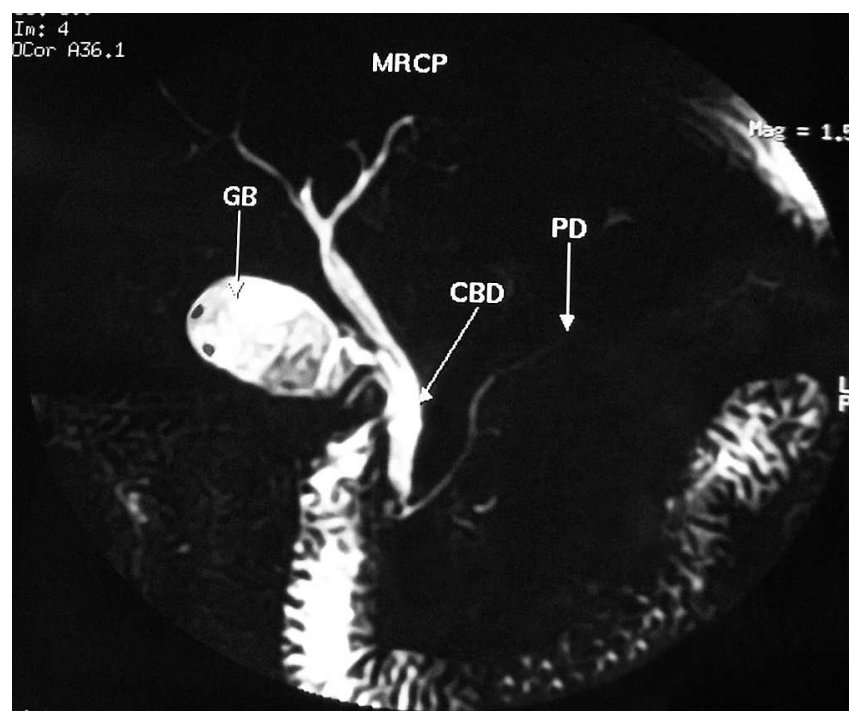

Fig. 1 "Pseudo" gallbladder: magnetic resonance cholangiopancreatogram (MRCP) showing an appearance that closely resembles that of an anatomically intact gallbladder (GB) with multiple stones. The common bile duct (CBD) and pancreatic duct (PD) were normal.

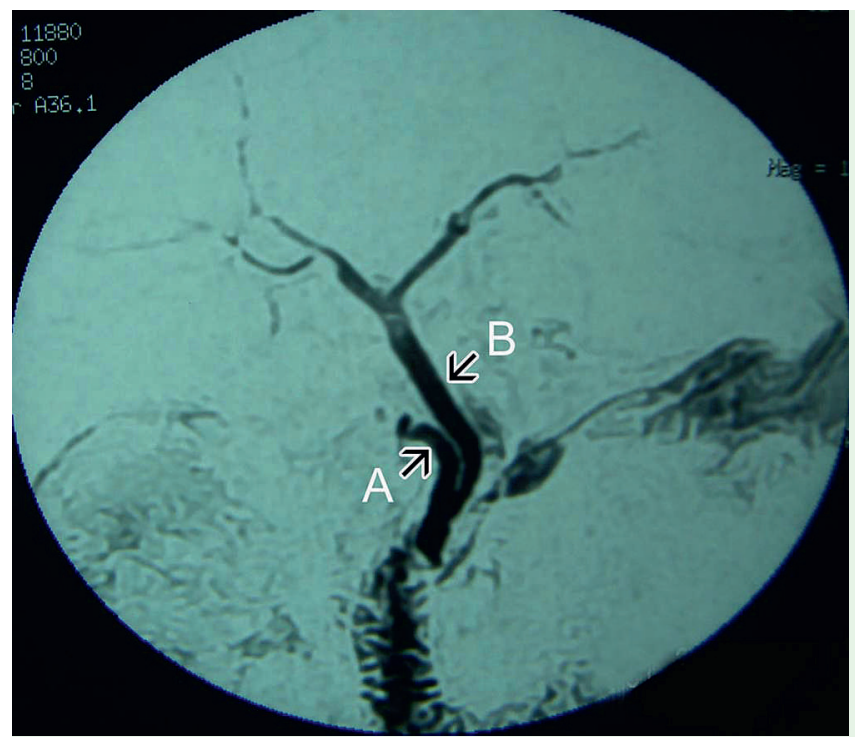

Fig. 2 MRCP of the same patient showing low insertion of cystic duct (A) into the common bile duct (B).

trauma. However, gallbladder perforation should be avoided as far as possible. If it occurs, all spilled stones should be retrieved and the patient informed. Moreover, routine use of endobags for specimen retrieval is strongly recommended in all laparoscopic cholecystectomies to avoid such potentially morbid sequelae.

Endoscopy_UCTN_Code_CCL_1AZ_2AD

\section{Palanivelu, P. A. Jategaonkar, M. Rangarajan, B. Srikanth} GEM Hospital and Postgraduate Institute, Ramnathapuram, Coimbatore, India 


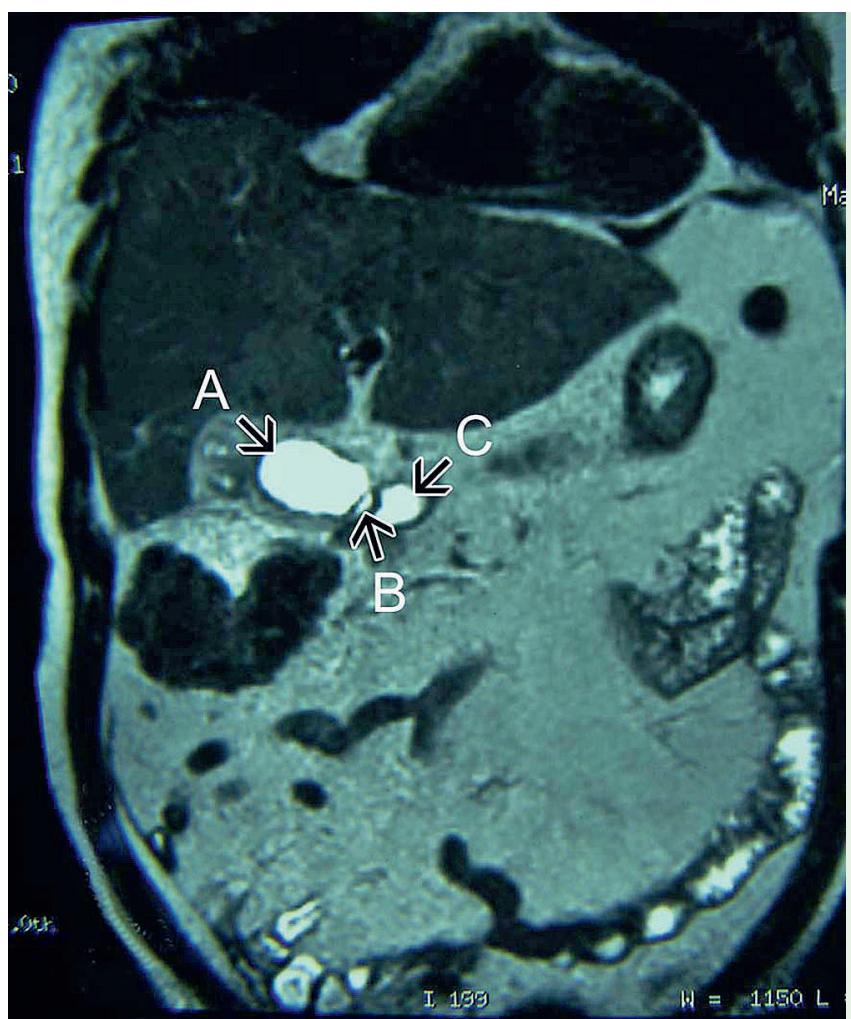

Fig. 3 Coronal section of magnetic resonance image showing "pseudo" gallbladder (A), "pseudo" cystic duct (B), and normal duodenum (C).

\section{References}

1 Sathesh-Kumar T, Saklani AP, Vinayagam R, Blackett RL. Spilled gall stones during laparoscopic cholecystectomy: a review of the literature. Postgrad Med J 2004; 80: 77-79

2 Schäfer M, Suter C, Klaiber $C$ et al. Spilled gallstones after laparoscopic cholecystectomy. A relevant problem? A retrospective analysis of 10174 laparoscopic cholecystectomies. Surg Endosc 1998; 12: 305 - 309

3 Brueggemeyer MT, Saba AK, Thibodeaux LC. Abscess formation following spilled gallstones during laparascopic cholecystectomy. JSLS 1997; 1: 145 - 152

Bibliography

DOI 10.1055/s-0029-1214633

Endoscopy 2009; 41: E186-E187

(c) Georg Thieme Verlag KG Stuttgart · New York . ISSN 0013-726X

\section{Corresponding author}

\section{Palanivelu, MD}

GEM Hospital and Postgraduate Institute

45-A, Pankaja Mill Road

Ramnathapuram

Coimbatore - 641045

India

Fax: +91-422-2320879

drcp@gemhospital.net 